\title{
Dealing with personal pensions complaints under the FSA
}

Received: 21st August, 2000

\begin{abstract}
Alistair MacDougall
is a founding Director of R-M Associates, a Management and Training Consultancy which provides risk management and compliance services as well as management and sales training. He has over 28 years of varied and practical experience within the financial services industry. Following a period with a leading UK insurer, Alistair worked for 18 years in the large IFA sector, holding various senior positions, including Business Process Director and Training and Development Director.
\end{abstract}

\begin{abstract}
This paper looks at the requirements for handling complaints under the Financial Services Authority's new rules and guidelines. The likely impact of the new integrated Financial Ombudsman Service (FOS), which will replace eight existing Ombudsman Schemes, is also considered. While the Pensions Ombudsman and the related Pensions Advisory Service (OPAS) will continue to operate separately from the FOS, almost all complaints concerning Group or Individual Personal Pensions will be handled under the new FOS arrangements. Accordingly, this paper will be of relevance to anyone involved in the running of personal pension arrangements.
\end{abstract}

Keywords: complaint; ombudsman; OPAS, personal pension

\section{Introduction}

Consultative paper CP33 sought views on the Financial Services Authority's (FSA) proposed complaints handling rules and the proposals for a single

Ombudsman scheme. Consultative paper CP49 contained a summary of the responses to CP33 and indicated the way in which the FSA intended to proceed, having taken the responses into account.

An annex to CP49 contains the draft rules.

These new rules will apply to all regulated firms unless they apply for exemption in advance and then certify annually that they do not conduct

Alistair MacDougall (R-M Associates, Lorne House, Frank's Lane, Whixley, York YO26 8AP, UK.

Tel: $+44(0) 1423331627$; e-mail: amd@rmassociates.net) business which could give rise to an eligible complaint. This is known as the Compulsory Jurisdiction.

However, firms can choose to be covered under the rules even where not required to do so. This is known as the
Voluntary Jurisdiction and is based on a contractual arrangement using the FSA 'Standard Terms'.

When it comes into existence (the timing is not confirmed at time of writing), the Financial Ombudsman Service (FOS) will replace eight previously separate Ombudsman schemes, namely:

- The PIAOB

- The Investment Ombudsman

- The SFA Complaints Bureau

- The FSA Independent Investigator

- The Banking Ombudsman

- The Building Societies Ombudsman

- The Insurance Ombudsman

- The Personal Insurance Arbitration Service.

However, it is important to note that the Pensions Ombudsman and the 
related Pensions Advisory Service (OPAS) will remain as separate entities from the FOS. So how is this relevant to handling complaints about Personal Pensions?

The answer is that, while the Pensions Ombudsman's remit does include the mismanagement of Personal Pensions, almost all complaints concerning these are, in practice, dealt with by the PIAOB at present and so will come under the new FOS arrangements.

\section{Overview of the FSA Complaints Rules}

The rules are a single coherent set covering all of the subsets of the FSA's regulated areas rather than a different set of rules for each of the previous regulated categories (PIA, IMRO etc). They are part of the block on 'Redress' and will follow the sequence of the complaints handling process.

They are divided into four chapters, each covering one of the following four areas:

— complaint handling procedures for firms

— jurisdiction of the FOS

- complaint handling procedures of the FOS

— Standard Terms.

\section{The complaints handling procedures in} detail

- Effective procedures for handling complaints must be in place and they must comply with the FSA rules and guidance.

- The firm's complaints procedures must be documented and available on request. They must be provided at the first opportunity to all complainants. Furthermore, their availability must be referred to at the point of sale.

- The fact that the firm is covered by the Financial Ombudsman Service must be mentioned on all stationery and marketing literature. (Firms have a transition up to 1st January, 2002 to comply fully with this requirement.)

- Firms must report twice yearly to the FSA with details of number of complaints, broken down into predefined categories, number completed in four and eight weeks and the number accepted as valid complaints.

\section{What constitutes a complaint}

A complaint is defined in the rules as 'any expression of dissatisfaction, oral or written, serious or trivial.'

However, full reporting requirements and FOS referral only apply where the complainant alleges 'financial loss, or material distress or inconvenience'.

Firms need not treat as a complaint one which, to the knowledge of the firm, does not fall within the jurisdiction of the Financial Ombudsman Service.

\section{Time limits}

\section{Four weeks}

The FSA expects most complaints to be completed within a four-week period. (Completed means that the firm have issued a 'final response', ie, accepting the claim and resolving the matter appropriately or rejecting the claim). Where the complaint is not yet completed by the four-week point, a holding letter must be sent advising progress.

\section{Eight weeks}

If a final response cannot be issued by the eight-week point then a letter must be issued advising anticipated progress 
but informing the complainant of the right to refer the matter to the FOS and issuing the FOS leaflet. Note that the complainant can choose to await the final response rather than refer to FOS at this point.

\section{Six months}

The complainant has six months from the 'final response' letter to refer to the FOS.

\section{Six (or three) years}

However, referrals will only be considered where within six years of the event which gave rise to the complaint or within three years of when the complainant ought reasonably to have been aware of a cause for complaint.

\section{Six years}

Records must be retained for six years from the date of a complaint including the name of the complainant, the substance of the complaint, any correspondence between the firm and the complainant and details of any redress offered.

\section{Other key points}

- All 'relevant' staff and appointed representatives must be made aware of the procedures and definitions of complaints. It is vital for all firms concerned with Personal Pensions to understand whether and how this is achieved.

- Firms must have adequate management controls in place to ensure that all complaints are handled fairly, consistently and promptly. This means using the complaints records positively as a means of driving quality in the process.

- As well as taking appropriate action to remedy any issues arising from the specific complaint, firms must identify and remedy any recurring or systemic problems. There is no point in having a wonderfully efficient complaints handling process, if the business does not learn and improve as a result of the stark customer feedback which complaints represent.

\section{Overview of the Financial Ombudsman Service}

The integrated FOS covers all regulated firms except those which are exempt (see earlier reference). The FOS process also applies to Voluntary Jurisdiction participants.

There is a limit of $£ 100,000$ on awards. This is consistent with the limitations on who can use the service. The FOS is aimed at 'smaller' claims and claimants. The rationale is that for larger claims and/or well resourced claimants, there is more likelihood of the claim being pursued through the courts. This does not, however, mean that the FOS is only available to private individuals. The scope of claimants is shown below.

The FOS is open to:

- Private Individuals

- 'Small Businesses', defined as those with annual turnover of less than f1m. (In the case of Charities, the $11 \mathrm{~m}$ applies to annual income. For trustees, it is the net assets of the trust which are counted.)

- Third parties, ie, those who are not direct contracting parties. For example, employees in a Group Life Scheme effected by their employer if the policy confers a benefit on the employee (as distinct from the employer).

It should be noted that agents for all of the above are also entitled to use the scheme. 
Personal Pension members are covered by dint of their direct contractual link to the provider, even in a 'Group' Personal Pension Scheme.

The FOS will not consider complaints until the firm has had the full eight weeks mentioned earlier in which to issue a final response. The FOS will not consider complaints which are 'out of time' (beyond six months or statutory limits) other than in exceptional circumstances (which are outlined in the rules).

Costs can be awarded to the complainant but not against the complainant. The FOS will have regard to the differing levels of experience and expertise in complainants when reaching its verdict.

\section{Who complains}

Research carried out on behalf of the FSA in 1999 indicated that 'one in four' people have something to complain about, although many do not actually complain, and this may say something about the reluctance of British people to complain. The main complaints are about service or rude staff.

Even after they make a complaint, over 40 per cent remain unhappy with the way the complaint is handled, yet 90 per cent of them do not take matters further, eg, to an Ombudsman.

No good organisation should seek to rely on these findings to fuel a complacent attitude towards customers who complain or a half-hearted approach to handling complaints. It is bad enough to get a complaint but worse to realise that many of your customers may simply walk away, becoming a customer of a competitor and offering no chance for the firm to remedy the situation which gave rise to the complaint. Even where a complaint is actually received, if the firm does not handle it in a positive manner, then the opportunity is lost to turn it into a learning experience for the organisation and its staff and to turn a customer with a grievance into a customer who appreciates the professionalism of a firm which recognises and remedies its failings.

\section{Regional variations}

The same research also showed some noteworthy regional variations. In Yorkshire, complaints are much less likely to be settled happily than elsewhere. Around half were dissatisfied, yet only 6 per cent took it further, leaving a massive 46 per cent to go away unhappy and spread the news around their friends and colleagues. The statistics about how many more people are told about a poor experience with an organisation as compared with the number told about good service or whatever are widely known.

In London and the South East, people make more complaints and have more problems with financial institutions than anywhere else in England. Again around half were not satisfied with the response to their complaint, yet 90 per cent did not take it further.

In Scotland, consumers have more problems with financial institutions than anywhere else in Britain. But at least the Scots complain more than others! Most complaints were about overcharging, mistakes, poor service or rude staff.

All this just serves to strengthen the case that there is much still required to improve the quality of customer care of many financial organisations in the UK. Since, in the real world, things will always go wrong occasionally, it is vital for firms to see a complaint as an 'opportunity in work clothes'.

The real test of an organisation is not how it cares for its customers but how it cares for its unhappy customers. 


\section{Dealing with complaints effectively}

There is a vicious circle which surrounds dealing with unhappy customers. The ideal is not to get on the circle in the first place but, in the real world, problems do arise.

Thus the trick becomes one of getting off the circle at earliest possible exit.

- First you become aware of a problem or innocent sounding query. If you deal with the problem well, it need never become a complaint.

- If it does escalate to a complaint, then dealing with it well may prevent it reaching the Ombudsman.

- Working well if you are in an Ombudsman situation can avoid legal action.

- And, of course, nobody wins if the matter ends up in court!

So how can you ensure you make an early exit?

\section{Avoiding the complaint}

- Encourage feedback from all of your customers, not just those who are happy or those who are not. Build in some means whereby they can tell you about their experience of dealing with you by invitation and ensure they know who to call if they wish to make any comment at any time.

- Ensure all staff are aware of how to deal with customer queries, and recognise when these might escalate into a problem or a complaint. Encourage a customer-first approach, in which all staff know that they are there for the sole purpose of serving the customer, no matter how distant they are from the 'front line'.

- First impressions count - customers who feel their concern is being treated seriously and professionally will be less likely to escalate the problem. Make sure your front line people are empowered as far as possible to deal with the issue adequately.

- Do not defend the indefensible - if the query, problem or complaint is valid, accept it readily, and with good grace. Apologise and sort it rapidly so that the customer's issue is resolved.

\section{Avoiding the Ombudsman}

If the matter does escalate to the complaints stage, or its nature means that it must be treated as such, then you can still keep control of the situation such that your customer can readily see that you are treating the matter seriously and objectively and with a view to remedying the situation where required, not defending your corner regardless of the rights and wrongs of the case.

(As an aside, some firms have a practice, on receiving a solicitor's letter on behalf of a customer, to refer the matter to their legal department or outside lawyers. It has been known for some solicitors to approach the complaint in a way which 'defends' their client, omitting details of the case, rather than dealing with the complaint fairly and openly as is required by the regulator. Make sure your firm's solicitors are up to speed on this aspect.)

- Again first impressions count and an early comfort in the complainant's mind that the firm will be fair will go a long way in reaching an amicable and equitable solution.

- Remember that the complainant is, first and foremost, still a customer who is entitled to the benefit of a customer-first approach.

- Ensure your procedures are fully compliant and that staff implement them correctly. 
- The time limits should be considered as 'deadline opportunities' eg, at the four weeks point, you have an extra chance to remind the customer how you are dealing with things and that you are keen to resolve the matter even if you cannot do so immediately. Similar positive messages can be given at the eight weeks point or at the final response point.

\section{A complaint or an opportunity?}

Remember the earlier suggestion that each complaint might actually be an 'opportunity in work clothes'? In what ways can it be an opportunity?

First, even if a firm has little or no proactive ways to capture feedback from its customers, each complaint is feedback of the most telling kind and is usually not hidden in 'customer survey response speak'. Given the earlier statistics about how small the proportion of customers who actually complain, a firm can be sure that those who do complain feel strongly about what they are telling the organisation.
Secondly, by pointing up real or perceived weaknesses in the firm's processes or people, there is a chance to do something about remedying those weaknesses, which not only minimises the likelihood of that problem recurring but also drives a process of continuous step improvements in the firm's capability to deal with customers in future.

There is no more loyal customer than one who has had the opportunity to be heard, and who knows that the firm is better because of his or her input.

Finally, receiving a complaint is miles better than the alternative - not receiving the complaint, but instead losing the customer to a competitor, not knowing why, and losing out on the chance to improve your performance for other customers.

\section{Postscript}

Since the time of writing, the Treasury has announced that the relevant provisions in the Financial Services and Markets Act are not now expected to come into force until sometime in 2001. Accordingly, the new FSA complaints procedures will be delayed and will not take effect until this time. 